\title{
Effect of Heating Fuel through the Upper Tank Radiator with Copper Pipes Against Torque and Power
}

\section{Pengaruh Pemanasan Bahan Bakar Melalui Upper Tank Radiator Dengan Pipa Tembaga Terhadap Torsi Dan Daya}

\author{
Endrika Wahidri ${ }^{*}$, Erzeddin Alwi ${ }^{1}$, Remon Lapisa ${ }^{1}$
}

\begin{abstract}
In an effort to improve motorcycle performance is done in various ways, one of which fuel warming through upper radiator tank with copper pipe. This is evidenced in this experimental study. The test results of heating fuel towards the torque and power of motorcycles $110 \mathrm{cc}$ Honda Vario using dyno test. Indicates that, the fuel warming influence on the torque and power of motorcycles in four steps. The average torque at $6500 \mathrm{rpm}$ engine rounds without a heater of $6.72 \mathrm{Nm}$ with an average torque at 6500 rpm engine using fuel warming through upper radiator tank with copper pipe of $7.07 \mathrm{Nm}$. With the increased torque of $0.35 \mathrm{Nm}$ or $4.95 \%$. While the average Power without the heater on the engine rpm of 8000 rounds $6.3 \mathrm{HP}$ with average power use of heating fuel through the upper radiator tank with copper pipe of $6.8 \mathrm{HP}$ at 8000 rpm engine rotation. With the increased power of 0.5 or $7.35 \%$.
\end{abstract}

\section{Keywords}

heating fuel through Upper Tank Radiators, Torque, Power.

\begin{abstract}
Abstrak
Dalam upaya meningkatkan kinerja sepeda motor dilakukan dengan berbagai cara, salah satunya pemanasan bahan bakar melalui tangki radiator atas dengan pipa tembaga. Hal ini dibuktikan dalam penelitian eksperimen ini. Hasil pengujian memanaskan bahan bakar terhadap torsi dan tenaga motor Honda Vario 110 cc menggunakan uji dyno. Menunjukkan bahwa, pengaruh pemanasan bahan bakar pada torsi dan kekuatan sepeda motor dalam empat langkah. Torsi rata-rata pada putaran mesin $6.500 \mathrm{rpm}$ tanpa pemanas $6,72 \mathrm{Nm}$ dengan torsi rata-rata pada mesin $6.500 \mathrm{rpm}$ menggunakan pemanasan bahan bakar melalui tangki radiator atas dengan pipa tembaga 7,07 $\mathrm{Nm}$. Dengan peningkatan torsi $0,35 \mathrm{Nm}$ atau 4,95\%. Sedangkan Daya rata-rata tanpa pemanas pada putaran mesin 8000 putaran 6,3 HP dengan daya rata-rata menggunakan bahan bakar pemanas melalui tangki radiator atas dengan pipa tembaga 6,8 HP pada putaran mesin $8000 \mathrm{rpm}$. Dengan peningkatan daya 0,5 atau $7,35 \%$.
\end{abstract}

\section{Kata Kunci}

pemanasan bahan bakar melalui Upper Tank Radiator, Torsi, Daya.

1 Jurusan Teknik Otomotif, Universitas Negeri Padang

Fakultas Teknik, Kampus UNP Air Tawar, Jl. Prof. Dr. Hamka, Padang

*endrika99wahidri@gmail.com

Submitted : December 15, 2018. Accepted : Febuary 13, 2019. Published : May 15, 2019 


\section{PENDAHULUAN}

Seiring berkembangnya ilmu pengetahuan dan teknologi, berbagai alat diciptakan untuk mempermudah dan menambah kenyaman manusia dalam mencukupi dan memenuhi kebutuhan. Diantaranya adalah dibidang otomotif, dimana dalam penggunaannya diperlukan pengetahuan tentang mesin sehingga dapat berjalan seefektif dan seefisien mungkin.

Karburator merupakan salah satu bagian suplay bahan bakar yang penting pada sepeda motor. Karburator berfungsi untuk mencampur bahan bakar dan udara dalam perbandingan yang tertentu sehingga menjadi gas pembakar yang dibutuhkan oleh mesin sepeda motor. Bahan bakar harus dapat terbakar keseluruhannya didalam ruang bakar untuk menghasilkan tenaga yang maksimal.

Sepeda motor yang menggunakan karburator sebagai pencampuran bahan bakar dan udara kurang baik, karena atomisasi campuran udara dan bahan bakar bensin yang kurang sempurna. Akibat dari atomisasi campuran yang kurang sempurna adalah adanya bahan bakar bensin yang tidak dapat terbakar dengan baik, sehingga energi yang didapat bahan bakar tidak maksimal untuk mendorong torak. Dorongan torak yang tidak maksimal mengakibatkan berkurangnya kemampuan mesin dalam menghasilkan torsi dan daya. Hal ini disebabkan oleh proses pembakaran yang kurang sempurna, dengan adanya sebagian bahan bakar yang tidak terbakar. Dengan kata lain sepeda motor karburator mengalami masalah pada efisiensi daya motor. Proses pembakaran didalam silinder dipengaruhi oleh beberapa faktor: temperatur bahan bakar, kerapatan campuran, komposisi, dan turbulensi yang ada pada campuran. Apabila temperatur bahan bakar dengan udara naik, maka semakin mudah campuran bahan bakar dengan udara tersebut untuk terbakar, sehingga menghasilkan daya ledak yang tinggi untuk mendorong piston secara maksimal[10]. Dengan temperatur yang cukup campuran bahan bakar dan udara akan terbakar dengan sempurna sehingga dapat meningkatkan efisiensi mesin.

Apabila kondisi ini terus berlangsung tanpa adanya upaya meningkatkan efisiensi daya motor yang menggunakan sistem bahan bakar karburator. Maka akan berdampak pada kurang maksimalnya performa mesin. Ada beberapa hal yang dapat meningkatkan kemampuan mesin dalam menghasilkan tenaga yang maksimal. Salah satunya adalah dengan cara meningkatkan efisiensi kerja motor dan efisiensi pemasukan campuran bahan bakar dan udara, yaitu dengan melakukan pemanasan atau menaikkan temperatur bahan bakar. Hal ini dapat membantu memaksimalkan efisiensi pemasukan campuran bahan bakar dan udara serta efisiensi daya motor pada mesin. Dengan menambah suplay bahan bakar yang semula cair setelah dinaikkan temperatur bahan bakarnya akan lebih cepat menguap dan bertekanan, sehingga dapat meningkatkan kemampuan mesin dalam menghasilkan tenaga yang maksimal, yaitu torsi dan daya mesin.

Berdasarkan penjelasan yang telah dipaparkan, untuk mengatasi masalah tersebut agar menghasilkan tenaga yang maksimal dapat dilakukan dengan metode pemanasan atau menaikkan temperatur bahan bakar. Metode pemanasan adalah mengalirkan bahan bakar pada saluran bahan bakar melewati media pemanas. Proses pemanasan bahan bakar dapat membuat pembakaran lebih sempurna, sehingga dapat meningkatkan torsi dan daya mesin sepeda motor karburator. Maka dengan cara ini bahan bakar dipanaskan pada upper tank radiator dengan memanfaatkan panas air pendingin radiator. Dengan membuat saluran bahan bakar yang terbuat dari pipa tembaga melalui upper tank radiator, maka sebelum bahan bakar tercampur dengan udara bahan bakar dapat menguap dan betekanan, sehingga mempercepat dan memperbanyak pemasukan pencampuran bahan bakar dan udara didalam karburator. Dengan hal ini akan terjadinya peningkatan terhadap peforma mesin dalam menghasilkan torsi dan daya sepeda motor empat langkah. 


\section{DASAR TEORI}

\section{Pemanasan bahan bakar}

Pemanasan bahan bakar adalah proses menaikkan temperatur bahan bakar dari temperatur normalnya. Apabila bahan bakar dengan temperatur awal $\mathrm{T}_{0}{ }^{\circ} \mathrm{C}$ dalam keadaan diam, maka pada saat dipanaskan dengan temperatur akhir $\mathrm{T}_{\mathrm{n}}{ }^{\circ} \mathrm{C}$ akan mengakibatkan perubahan pergerakan fluida atau bahan bakar, karena adanya pergerakan akibat pemanasan tersebut maka kemampuan molekul bahan bakar melepaskan diri dari lingkungannya menjadi lebih cepat sehingga mempermudah proses pengabutan bahan bakar pada ruang bakar yang berkorelasi dengan performa mesin.

Dalam pemanasan bahan bakar harus sesuai dengan temperatur kerja yang dimiliki bahan bakar. Beberapa hal yang harus diperhatikan dalam pemanasan bahan bakar yaitu flash point dan fire point bahan bakar agar tidak terjadinya peristiwa terbakarnya bahan bakar dengan sendirinya akibat pemanasan mencapai temperatur fire point-nya (auto ignition). Selain memperhatikan temperatur bahan bakar, temperatur kerja mesin pada saat terjadi pembakaran (ignition) juga perlu mendapat perhatian agar tidak terjadi detonasi pada ruang bakar[9].

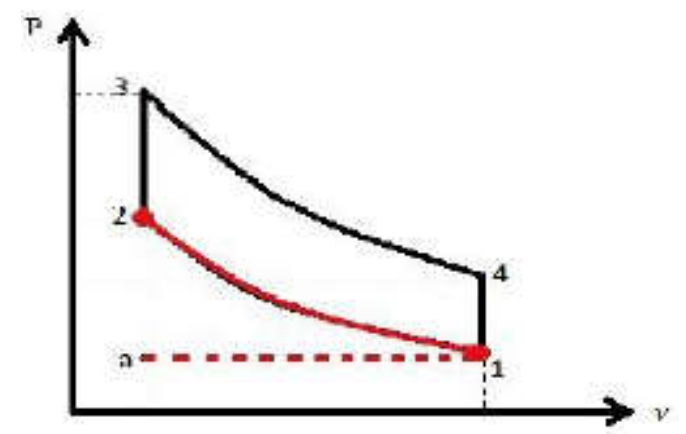

Gambar 1. Diagram P-V [11].

Siklus baku udara otto terdiri dari proses - proses reversibel sebagai berikut:

1. Proses 1-2, kompresi secara adiabatis $(Q=0)$

2. Proses 2-3, pemasukkan panas secara isochoris ( $\mathrm{V}=$ konstan)

3. Proses 3-4, ekspansi secara adiabatis $(\mathrm{Q}=0)$

4. Proses 4-1, pengeluaran panas secara isochoris (V=konstan)

Disamping itu boleh mempertimbangkan langkah buang 1- a dan langkah hisap a-1, untuk melengkapi meskipun ini tidak perlu [4].

\section{Analisa Termodinamika Diagram P-V Berdasarkan Proses 1 - 2}

Proses 1 - 2 : Langkah kompresi isentropik, semua katup tertutup. Piston bergerak dari titik mati bawah (TMB) ke titik mati atas (TMA).

Temperatur pada titik 2 .

Campuran bahan bakar dan udara yang dimampatkan oleh piston yang bergerak ke titik mati atas (TMA) juga mengakibatkan temperatur dalam silinder naik menjadi $\mathrm{T}_{2}$.

$$
\begin{aligned}
& T \cdot V^{k-1}=C \\
& T_{1} \cdot V_{1}^{k-1}=T_{2} \cdot V_{2}^{K-1} \\
& \frac{T_{1}}{T_{2}}=\left(\frac{V_{2}}{V_{1}}\right)^{K-1} \quad \text { Dimana, } \frac{V_{1}}{V_{2}}=r \rightarrow \frac{V_{2}}{V_{1}}=\frac{1}{r} \\
& \text { Maka, } \frac{T_{1}}{T_{2}}=\frac{1}{r^{k-1}}
\end{aligned}
$$




$$
\begin{aligned}
& T_{2}=T_{1} \cdot r^{k-1} \\
& T_{2}=49^{\circ} \mathrm{C} \cdot 10,7^{1,4-1} \\
& T_{2}=49^{\circ} \mathrm{C} .2,580 \\
& T_{2}=126,42^{\circ} \mathrm{C}
\end{aligned}
$$

Berdasarkan perhitungan diatas maka, temperatur pemanasan bahan bakar $\mathrm{T}_{2}$ adalah $126,42{ }^{\circ} \mathrm{C}$ tidak melewati temperatur nyala /flash point bahan bakar itu sendiri. Temperatur nyala dengan sendirinya tanpa ada pengaruh api dari luar bensin adalah $\pm 380{ }^{\circ} \mathrm{C}$ [12]. Jadi temperatur pemanasan bahan bakar $\mathrm{T}_{2}$ tidak boleh melewati temperatur nyala ( flash point ) dari bahan bakar itu sendiri atau $\mathrm{T}_{2}<\mathrm{T}_{\text {siT. }}$. Agar tidak terjadinya pre-ignition (campuran bahan bakar terbakar dengan sendirinya). Sehingga tidak mengurangi daya ledak dari campuran bahan bakar dengan udara maka sebaliknya akan menambah daya ledak dari bahan bakar itu sendiri.

\section{Torsi}

Torsi pada mesin motor bakar ialah besarnya tenaga yang dihasilkan dari porses pembakaran bahan bakar dalam ruang bakar, sehingga tenaga yang dihasilkan tersebut dapat mendorong torak yang akhirnya memutar poros engkol dan menggerakan kendaraan. Alat yang digunakan untuk mengukur torsi dan daya yang dihasilkan mesin kendaraan adalah Dynamometer. Satuan Torsi ialah Nm.

\section{Daya}

Daya merupakan besarnya kerja yang dapat dilakukan dalam waktu tertentu. Sedangkan satuan ukuran untuk daya adalah Horse Power (HP).

\section{Alat Eksperimen}

Dalam penelitian ini menggunakan konsep pemanasan pada radiator dengan membuat saluran dengan pipa tembaga yang dimodifikasi pada upper tank radiator. Alat yang digunakan sebagai pemanas bahan bakar sebagai berikut:

\section{Radiator}

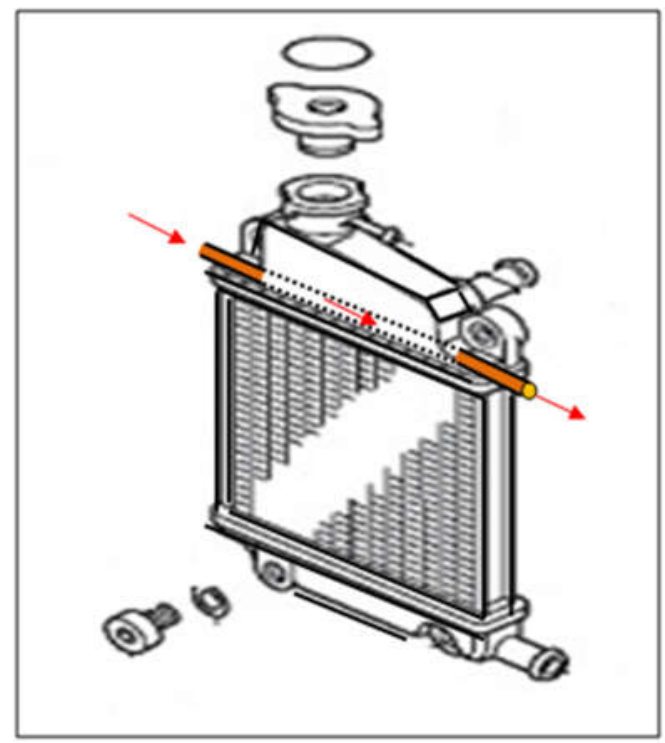

Gambar 2. Pemasangan Pipa Tembaga pada Upper Tank Radiator.

\section{Pipa Tembaga}

Pipa tembaga digunakan untuk menyalurkan bahan bakar dari fuel tank/ tangki bahan bakar sebelum masuk ke karburator. Bahan penghantar yang paling banyak digunakan adalah 
tembaga, karena tembaga merupakan bahan penghantar yang paling baik setelah emas dan harganya pun murah karena banyak terdapat dimana-mana atau bahan yang mudah didapat. Pipa tembaga memiliki sifat terutama dalam hal konduktivitas listrik dan juga memiliki sifat yang baik dalam hal konduktivitas panas atau bisa dikatakan penghantar panas yang baik. Pipa tembaga sangat mudah disambung melalui proses penyolderan serta pengelasan. Pipa tembaga termasuk golongan logam berat dimana memiliki titik lebur $1.085^{\circ} \mathrm{C}$. [1].

Pipa tembaga yang digunakan dalam penelitian ini berdiameter $5 \mathrm{~mm}$ sebanyak 1 pipa dengan panjang keseluruhan $420 \mathrm{~mm}$. Pipa tembaga akan di pasang di upper tank radiator sebagai tempat mengalirnya bahan bakar dari fuel tank/ tangki bahan bakar sebelum ke karburator. Bahan bakar yang mengalir didalam pipa tembaga akan terkonveksi panas dari fluida yang ada pada radiator, sehingga bahan bakar akan mendapatkan pertambahan nilai kalori bakar, dan bahan bakar semula cair akan berubah menjadi bahan bakar setengah gas.

3. Cara Kerja Alat Pemindah Panas dari Pipa Tembaga Pada Upper Tank Radiator

Pada dasarnya prinsip kerja dari alat penukar kalor (heat exchanger) yaitu memindahkan panas dari dua fluida pada temperatur berbeda di mana transfer panas dilakukan secara kontak tidak langsung, yaitu Perpindahan panas terjadi antara fluida panas dan dingin melalui dinding pemisah, yaitu pipa tembaga. Dalam sistem ini, kedua fluida akan mengalir.

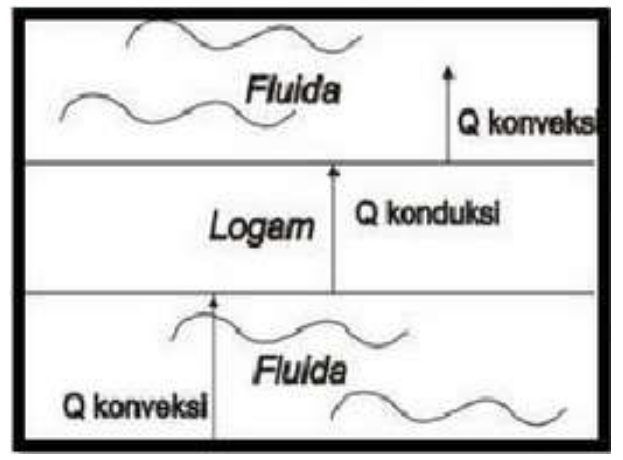

Gambar 3. Perpindahan Panas pada Heat Exchanger[3].

Bahan bakar yang ada dalam fuel tank di suplai ke karburator mengalir melalui pipa tembaga yang berada pada upper tank Radiator. Pada saat air radiator pada upper tank radiator sudah mencapai suhu kerja mesin atau suhu air radiator mencapai $80-90^{\circ} \mathrm{C}$. Maka pipa tembaga yang berada pada upper tank radiator otomatis mengalami kenaikan suhu dari suhu normalnya sehingga pipa tembaga menjadi panas dan bahan bakar yang berada dalam pipa tembaga akan terkonveksi panas dari pipa tembaga sehingga mengalami kenaikan suhu dari suhu normalnya. Oleh sebab itu bahan bakar yang berada dalam pipa tembaga menjadi panas yang disebabkan oleh panas air radiator yang berada pada upper tank radiator.

d. Pemasangan Pemanasan Bahan Bakar melalui Upper Tank Radiator dengan Pipa Tembaga pada Sepeda Motor

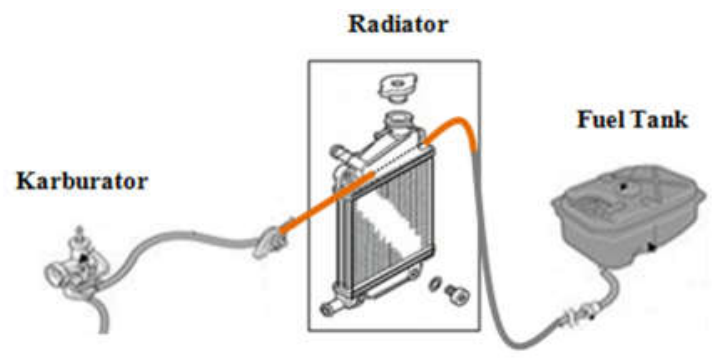

Gambar 4. Skema Pemasangan Aliran Pemanasan Bahan Bakar melalui Upper Tank Radiator pada sepeda motor 


\section{METODE PENELITIAN}

Penelitian eksperimen dimaksudkan untuk mengetahui pengaruh dari treatment (perlakuan) yang diberikan pada objek penelitian. Metode penelitian eksperimen dapat diartikan sebagai metode penelitian yang digunakan untuk mencari pengaruh perlakuan tertentu terhadap yang lain dalam kondisi yang terkendalikan [9].

\section{Tempat Penelitian}

Tempat penelitian dan pengujian ini dilakukan di Draco Motor yang beralamat di Jl. Durian, Simpang TVRI No. 21C Kota Pekanbaru, Propinsi Riau. Pada Tanggal 19 Juli 2017.

\section{Objek Penelitian}

Tabel 1. Spesifikasi Mesin Honda Vario[5].

\begin{tabular}{|l|l|}
\multicolumn{2}{|c|}{ Spesifikasi Mesin } \\
\hline Tipe Mesin & $\begin{array}{l}\text { Mesin SOHC, 4 } \\
\text { langkah }\end{array}$ \\
\hline Sistem Bahan Bakar & $\begin{array}{l}\text { Konvensional } \\
\text { (Karburator) }\end{array}$ \\
\hline Sistem Pendingin & Cairan \\
\hline Sistem Pengapian & DC-CDI, baterai \\
\hline Diameter x Langkah & $50 \mathrm{~mm}$ x 55mm \\
\hline Volume Langkah & $108 \mathrm{cc}$ \\
\hline Perbandingan Kompresi & 10,7 \\
\hline Daya Maksimum & $\begin{array}{l}8,86 \mathrm{HP} / 8000 \\
\mathrm{rpm}\end{array}$ \\
\hline Torsi Maksimum & $\begin{array}{l}8,43 \mathrm{Nm} / 6500 \\
\mathrm{rpm}\end{array}$ \\
\hline
\end{tabular}

Pada Spesifikasi mesin honda vario diatas, Dalam melakukan penelitian ini. peneliti hanya mengambil data spek putaran mesin pada $8000 \mathrm{rpm}$ untuk daya dan $6500 \mathrm{rpm}$ untuk torsi sebagai acuan. Untuk membandingkan Torsi dan daya yang dihasilkan pada sepeda motor kondisi yang sebenarnya dan dengan pengujian menggunakan pemanasan bahan bakar melalui upper tank radiator dengan pipa tembaga. Jadi bila hasil pengujian daya dan torsi yang didapat nanti tidak sama dengan data spesifikasi diatas dengan data empiris, karena itu sebagai acuan. Spek daya dan torsi diatas sepeda motor kondisi baru keluar pabrikan, sedangkan dalam penelitian ini. Pengujian dilakukan pada sepeda motor kondisi sebenarnya atau yang sudah lama digunakan.

\section{Teknik Analisa Data}

Untuk menganalisa keseluruhan data yang diperoleh serta mengetahui hasil penelitian peforma mesin sepeda motor dengan pemanasan bahan bakar melalui upper tank radiator dan tanpa pemanasan bahan bakar melalui upper tank radiator maka dapat dilakukan analisa sebagai berikut :

1. Data yang diperoleh langsung dari alat uji dynotest. Pengambilan data dilakukan sebanyak 3 kali pengujian dan data yang diambil pada torsi dan daya maksimal yang ada pada grafik.

Data torsi dan daya maksimum yang dihasilkan sepeda motor maupun putaran mesin, diperoleh langsung hasil pengujian menggunakan dynotest. Data yang diperoleh dalam bentuk print-out dengan informasi torsi, daya dan putaran mesin dalam bentuk grafik.

2. Menganalisis data dengan rumus statistik mean 
Menganalisa data dalam penelitian ini adalah dengan menggunakan perhitungan statistik mean atau rata - rata.

Adapun rumus yang digunakan adalah sebagai berikut :

$$
\bar{X}=\frac{\sum X}{n} \quad \cdots[\text { [7] }
$$

Keterangan:

$$
\begin{aligned}
& \bar{X} \quad=\text { Mean (rata-rata) } \\
& \sum x=\text { Jumlah data setiap- } \\
& \text { spesimen pengujian } \\
& n \quad=\text { Banyak pengujian per- } \\
& \text { spesimen }
\end{aligned}
$$

3. Setelah didapat rata-ratanya, kemudian membandingkan nilai rata-rata dari masing masing statistik dengan menggunakan teknik statistik deskriptif. Adapun rumus yang digunakan adalah rumus persentase.

$$
P=\frac{n-N}{n} \times 100 \%
$$

Keterangan:

$\mathrm{P}=$ Angka persentase yang ingin didapatkan.

$\mathrm{n}$ = Rata-rata setelah perlakuan pemanasan bahan bakar melalui upper tank radiator.

$\mathrm{N}$ = Rata-rata sebelum perlakuan/ kondisi standar.

Persentase bertujuan untuk mendapatkan gambaran seberapa besar pengaruh penggunaan pemanasan bahan bakar melalui upper tank radiator dan tanpa pemanasan/standar atau menemukan sesuatu sebagaimana adanya tentang objek yang diteliti.

\section{HASIL DAN PEMBAHASAN}

\section{Hasil}

Data Hasil Pengujian Torsi dan Daya Maksimum Sepeda Motor Empat Langkah Honda Vario $110 c c$

Tabel 2. Data Hasil Pengujian Torsi Sepeda Motor Dengan Dyno test.

\begin{tabular}{|c|c|c|c|c|c|c|}
\hline \multirow{2}{*}{ Uji } & \multicolumn{3}{|c|}{ Kondisi Standar } & \multicolumn{4}{|c|}{ Pemanasan Bahan - Bakar } \\
\cline { 2 - 7 } & $\begin{array}{c}\text { Torsi } \\
(\mathrm{N} . \mathrm{m})\end{array}$ & RPM & $\begin{array}{c}\mathrm{T}_{\text {in }} \\
\left({ }^{\circ} \mathrm{C}\right)\end{array}$ & $\begin{array}{c}\mathrm{T}_{\text {out }} \\
\left({ }^{\circ} \mathrm{C}\right)\end{array}$ & $\begin{array}{c}\text { Torsi } \\
(\mathrm{N.m})\end{array}$ & RPM \\
\hline 1 & 6,42 & 6500 & 33 & 49 & 7,27 & 6500 \\
\hline 2 & 6,98 & 6500 & 33 & 49 & 6,94 & 6500 \\
\hline 3 & 6,78 & 6500 & 33 & 49 & 7,01 & 6500 \\
\hline Total & 20,18 & 19500 & 33 & 49 & 21,22 & 19500 \\
\hline Rata-rata & $\mathbf{6 , 7 2}$ & $\mathbf{6 5 0 0}$ & $\mathbf{3 3}$ & $\mathbf{4 9}$ & $\mathbf{7 , 0 7}$ & $\mathbf{6 5 0 0}$ \\
\hline
\end{tabular}

Tabel 3. Data Hasil Pengujian Daya Sepeda Motor Dengan Dyno test 


\begin{tabular}{|c|c|c|c|c|c|c|}
\hline \multirow{2}{*}{ Uji } & \multicolumn{2}{|c|}{ Kondisi Standar } & \multicolumn{4}{|c|}{ Pemanasan Bahan - Bakar } \\
\cline { 2 - 7 } & $\begin{array}{c}\text { Daya } \\
(\mathrm{HP})\end{array}$ & RPM & $\begin{array}{c}\mathrm{T}_{\text {in }} \\
\left({ }^{\circ} \mathrm{C}\right)\end{array}$ & $\begin{array}{c}\mathrm{T}_{\text {out }} \\
\left({ }^{\circ} \mathrm{C}\right)\end{array}$ & $\begin{array}{c}\text { Daya } \\
(\mathrm{HP})\end{array}$ & RPM \\
\hline 1 & 5,9 & 8000 & 33 & 49 & 7,1 & 8000 \\
\hline 2 & 6,6 & 8000 & 33 & 49 & 6,6 & 8000 \\
\hline 3 & 6,6 & 8000 & 33 & 49 & 6,7 & 8000 \\
\hline Total & 19,1 & 24000 & 33 & 49 & 20,4 & 24000 \\
\hline Rata-rata & $\mathbf{6 , 3}$ & $\mathbf{8 0 0 0}$ & $\mathbf{3 3}$ & $\mathbf{4 9}$ & $\mathbf{6 , 8}$ & $\mathbf{8 0 0 0}$ \\
\hline
\end{tabular}

\section{Grafik Hasil Pengujian}

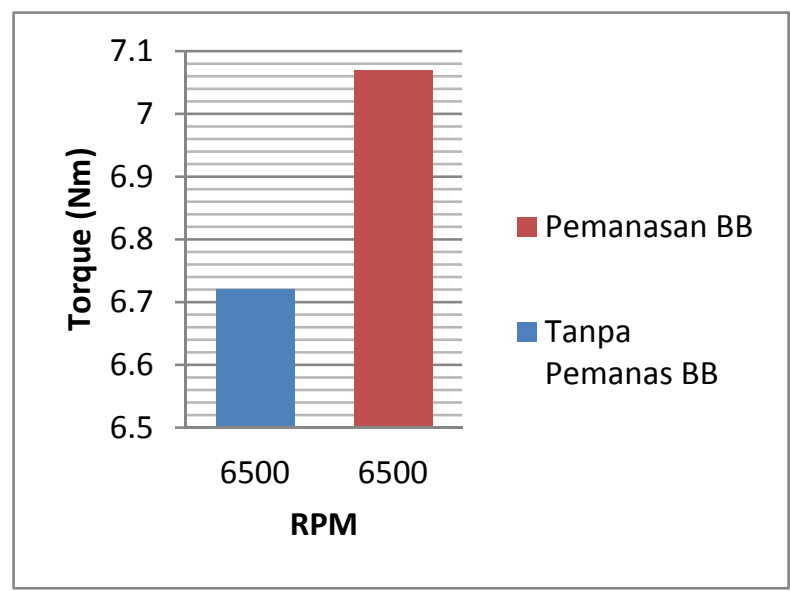

Gambar 5. Grafik Perbandingan Peningkatan Torsi Tanpa Pemanas Dan Dengan Pemanasan Bahan Bakar Melaui Upper Tank Radiator

Grafik di atas menunjukkan perbandingan peningkatan torsi pada Rpm 6500 yang dihasilkan sepeda motor tanpa pemanas dan dengan pemanasan bahan bakar melalui upper tank radiator. Warna biru menunjukkan grafik torsi sepeda motor dalam kondisi tanpa pemanasan dan warna merah torsi sepeda motor dengan pemanasan bahan bakar melalui upper tank radiator. Pada grafik dapat dilihat bahwa pemanasan bahan bakar melalui upper tank radiator dengan pipa tembaga berpengaruh terhadap torsi yang dihasilkan mesin sepeda motor empat langkah Honda Vario 110 cc. Terjadi peningkatan torsi pada rpm 6500 sebesar 6,72 Nm menjadi 7,07 Nm.

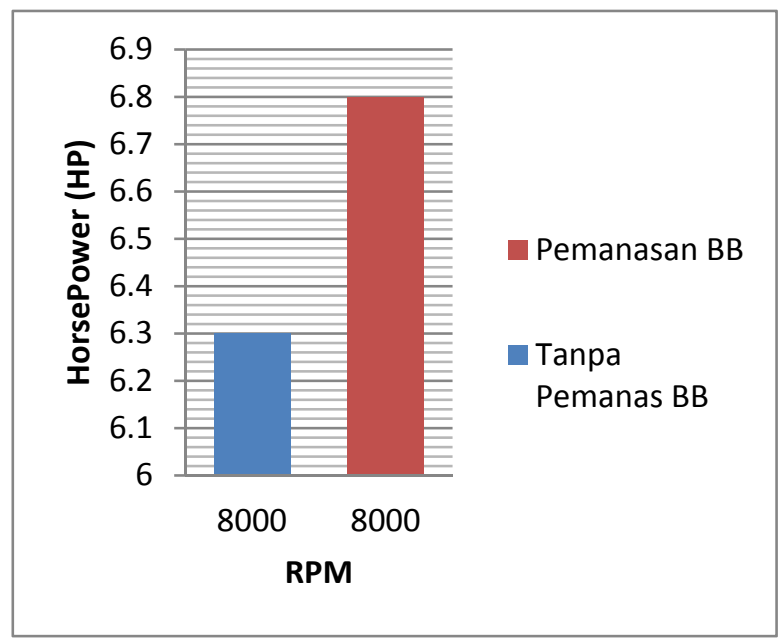


Gambar 6. Grafik Perbandingan Peningkatan Daya Tanpa Pemanas Dan- Dengan Pemanasan Bahan Bakar Melaui Upper Tank Radiator

Grafik di atas menunjukkan perbandingan peningkatan torsi pada Rpm 8000 yang dihasilkan sepeda motor tanpa pemanas dan dengan pemanasan bahan bakar melalui upper tank radiator dengan pipa tembaga. Warna biru menunjukkan grafik torsi sepeda motor dalam kondisi tanpa pemanasan dan warna merah torsi sepeda motor dengan pemanasan bahan bakar melalui upper tank radiator. Pada grafik dapat dilihat bahwa pemanasan bahan bakar melalui upper tank radiator dengan pipa tembaga berpengaruh terhadap torsi yang dihasilkan mesin sepeda motor empat langkah Honda Vario 110 cc. Terjadi peningkatan torsi pada rpm 8000 sebesar 6,3 HP menjadi 6,8 HP.

\section{Pembahasan}

\section{Analisis Torsi dan Daya}

Berdasarkan hasil pengujian torsi dan daya pada sepeda motor empat langkah Honda Vario karburator dengan penggunaan pemanasan bahan bakar melalui upper tank radiator dengan pipa tembaga. Dengan panjang pipa tembaga $420 \mathrm{~mm}$ berdiameter $5 \mathrm{~mm}$ dimana sebelumnya pipa tembaga dimasukkan pada upper tank radiator didapat kenaikan temperatur bahan bakar yang sebelumnya $\mathrm{T}_{\text {in }} 33^{\circ} \mathrm{C}$ menjadi $\mathrm{T}_{\text {out }} 49^{\circ} \mathrm{C}$. Kemudian dilakukan pengujian torsi dan daya dengan menggunakan Dyno test yang dapat dilihat pada tabel 2 dan 3 serta pada gambar grafik 5 , dan 6 .

Berdasakan pendapat Soedarmo (2008: 28) bahwa, Bahan bakar yang dikirim kedalam silinder mesin harus ada dalam kondisi mudah terbakar agar dapat menghasilkan efisiensi tenaga yang maksimum, bensin agak sulit terbakar apabila tidak diubah menjadi gas[8]. Maka dengan pemanasan bahan bakar atau menaikkan temperatur bahan bakar yang dipanaskan melalui upper tank radiator dengan pipa tembaga, akan mempengaruhi efisiensi pemasukan campuran bahan bakar sehingga bahan bakar yang semula cair setelah dipanaskan akan cepat menguap dan betekanan, sehingga mempercepat dan memperbanyak pemasukan pencampuran bahan bakar dan udara didalam karburator. Maka semakin mudah campuran bahan bakar dengan udara tersebut untuk terbakar, sehingga menghasilkan daya ledak yang tinggi untuk mendorong piston secara maksimal. Dengan temperatur yang cukup campuran bahan bakar dan udara akan terbakar dengan sempurna sehingga meningkatnya torsi dan daya mesin sepeda motor.

Hal ini sesuai yang dinyatakan Djokosetyardjo, (2006 : 64) bahwa, Sebelum pembakaran yang sebenarnya berlangsung, maka terlebih dahulu bahan bakar cair tersebut diuapkan dan diuraikan menjadi gas-gas. Hasil dari meningkatnya kualitas pembakaran seiring dengan meningkatnya temperatur bahan bakar yang masuk kedalam ruang bakar bersama udara menghasilkan tekanan dan temperatur yang tinggi pada awal langkah pembakaran sehingga dapat menekan torak dari TMA ke TMB dan akan menghasilkan torsi dan daya yang lebih tinggi dibandingkan tanpa pemanasan bahan bakar[2].

Torsi dipengaruhi oleh putaran mesin, dimana semakin meningkat putaran mesin semakin turun torsi yang dihasilkan hal ini disebabkan semakin tinggi putaran mesin maka semakin sedikit siklus pembakaran yang terjadi, sehingga torsi pun akan meningkat dan akan kembali menurun setelah mencapai titik maksimumnya pada putaran mesin tertentu. Sedangkan Daya, seperti yang dijelaskan sebelumnya hasil meningkatnya kualitas pembakaran pada ruang bakar mengakibatkan ledakan yang terjadi pada ruang bakar menjadi lebih besar dan kecepatan ledakan meningkat, ledakan inilah yang akan menghasilkan daya. 
Daya juga dipengaruhi oleh putaran mesin, dimana semakin meningkat putaran mesin maka daya yang dihasilkan akan semakin meningkat dan akan mengalami penurunan setelah melewati titik maksimumnya pada putaran tertentu. Hal ini disebabkan pada putaran yang semakin meningkat/ tingginya waktu yang diperlukan untuk membakar campuran bahan bakar semakin singkat. Hal ini sesuai yang dinyatakan pulkrabek (2004:56) ;

Torsi dan daya keduanya memiliki fungsi pada kecepatan mesin. Pada kecepatan rendah, torsi meningkat seiring meningkatnya kecepatan mesin. Ketika kecepatan mesin meningkat lebih lanjut, torsi mencapai titik maksimum dan kemudian menurun. Torsi berkurang karena mesin tidak dapat menelan muatan penuh dari udara pada kecepatan yang lebih tinggi. Daya indikator meningkat seiring dengan kecepatan mesin, daya meningkat hingga titik maksimum dan kemudian menurun di kecepatan yang lebih tinggi. Ini karena kerugian gesek meningkat seiring dengan kecepatan dan menjadi faktor yang dominan pada kecepatan yang sangat tinggi[6].

Analisis Pengaruh Pemanasan Bahan Bakar melalui Upper Tank Radiator dengan Pipa Tembaga Terhadap Torsi dan Daya

Dari data hasil penelitian, diperoleh bahwa pemanasan bahan bakar berpengaruh terhadap torsi dan daya sepeda motor empat langkah. Torsi rata-rata pada putaran mesin $6500 \mathrm{rpm}$ tanpa pemanas sebesar 6,72 Nm dengan torsi rata-rata pada putaran mesin 6500 rpm dengan menggunakan pemanasan bahan bakar melalui upper tank radiator dengan pipa tembaga sebesar 7,07 Nm. Dengan peningkatan torsi sebesar 0,35 $\mathrm{Nm}$ atau 4,95 \%. Sedangkan Daya rata-rata tanpa pemanas pada putaran mesin $8000 \mathrm{rpm}$ sebesar 6,3 HP dengan daya rata-rata menggunakan pemanasan bahan bakar melalui upper tank radiator dengan pipa tembaga sebesar 6,8 HP pada putaran mesin $8000 \mathrm{rpm}$. Dengan peningkatan daya sebesar 0,5 atau $7,35 \%$.

\section{SIMPULAN}

Adanya peningkatan torsi yang dihasilkan sepeda motor empat langkah honda vario 110 cc pada putaran mesin $6500 \mathrm{rpm}$ yaitu, dari 6,72 N.m dalam keadaan tanpa pemanasan bahan bakar melalui upper tank radiator dengan pipa tembaga, meningkat 0,35 N.m atau 4,95\% menjadi 7,07 N.m akibat dari pemanasan bahan bakar melalui upper tank radiator dengan pipa tembaga. Dan adanya peningkatan daya yang dihasilkan sepeda motor empat langkah honda vario 110 cc pada putaran mesin $8000 \mathrm{rpm}$ yaitu; dari 6,3 HP dalam keadaan tanpa pemanasan bahan bakar melalui upper tank radiator dengan pipa tembaga, meningkat 0,5 HP atau 7,35 \% menjadi 6,8 HP akibat penggunaan pemanasan bahan bakar melalui upper tank radiator dengan pipa tembaga.

Pemanasan bahan bakar melalui upper tank radiator berpengaruh terhadap torsi dan daya yang dihasilkan sepeda motor empat langkah honda vario 110cc karburator.

\section{DAFTAR RUJUKAN}

[1] Bondan T. Sofyan. 2010. Pengantar Material Teknik. Jakarta: Salemba Teknika.

[2] Djokosetyardjo, M.J. 2006. Ketel Uap. Jakarta: Pradnya Paramita.

[3] Djunaidi. 2009. "Pemeliharaan Tube\-Side Penukar Kalor Rsg-Gas Jangka Pendek Dan Jangka Panjang". Pusat Reaktor Serba Guna-BATAN. Kawasan Puspitek Serpong Tangerang : Banten.

[4] Ginting, Raja Ulungan. 1989. Dasar-dasar Termodinamika.Jakarta: P2LPTK.

[5] Honda. (2011). Buku Petunjuk Service. Jakarta: Honda Motor Ahass. 
[6] Pulkrabek, Williard. W. 2004. Engineering Fundamental of Internal Combustion Engine. New Jersey: Pearson Prentice-Hall.

[7] Sinambela, Lijan Poltak. 2014. Metodologi Penelitian Kuantitatif. Yogyakarta : Graha Ilmu.

[8] Soedarmo, Hartoto. 2008. Panduan Praktis Merawat Dan Memperbaiki Sepeda Motor. Jakarta: PT. Gramedia Pustaka Utama.

[9] Sugiyono. 2012. Metode Penelitian Kuantitatif, Kualitatif, dan R\&D. Bandung : Alfabeta.

[10] Suyanto, Wardan. 1989. Teori Motor Bensin. Jakarta: Proyek Pengembangan Lembaga Pendidikan Tenaga Kependidikan (P2LPTK).

[11] Tenaya, I Gusti Ngurah Putu dkk. 2013. "Pengaruh Pemanasan Bahan Bakar Dengan Media Radiator Pada Mesin Bertipe Injeksi Terhadap Unjuk Kerja Mesin”. Jurnal Energi dan Manufaktur, Volume 6 No 2. Oktober 2013: 95-202.

[12] Toyota. 1994. Materi Pelajaran Engine Group Step 2. Jakarta: PT. Toyota Astra Motor. 
